\title{
Emergence of barrel motif in amyloid- $\beta$ trimer: A computational study
}

\author{
Hoang Linh Nguyen, ${ }^{1,2,3}$ Huynh Quang Linh, ${ }^{2,3}$ Paolo Matteini ${ }^{4}$, Giovanni La Penna, ${ }^{5,6}$ and Mai \\ Suan $\mathrm{Li}^{7, *}$ \\ ${ }^{1}$ Institute for Computational Science and Technology, SBI Building, Quang Trung Software City, Tan \\ Chanh Hiep Ward, District12, Ho Chi Minh City 700000, Vietnam \\ ${ }^{2}$ Ho Chi Minh City University of Technology (HCMUT), Ho Chi Minh City 700000, Vietnam \\ ${ }^{3}$ Vietnam National University, Ho Chi Minh City 700000, Vietnam \\ ${ }^{4}$ Institute of Applied Physics "Nello Carrara", National Research Council, Via Madonna Del Piano 10, I- \\ 50019 Sesto Fiorentino, Italy \\ ${ }^{5}$ National Research Council of Italy (CNR), Institute for Chemistry of Organometallic Compounds \\ (ICCOM), 50019 Florence, Italy \\ ${ }^{6}$ National Institute for Nuclear Physics (INFN), Section of Roma-Tor Vergata \\ ${ }^{7}$ Institute of Physics, Polish Academy of Sciences, Al. Lotnikow 32/46, 02-668 Warsaw, Poland
}

E-mail: giovanni.lapenna@cnr.it; masli@ifpan.edu.pl

\section{Supporting Information}


Table S1: RSMD (nm) of regions of characteristic structures from free energy landscape of A $\beta 42$ trimer from simulation 2 at $300.38 \mathrm{~K}$. The reference structure is the initial conformation.

\begin{tabular}{|l|l|l|l|}
\hline Structure & N-terminus & Central & C-terminus \\
\hline S1 & 1.07 & 0.87 & 0.53 \\
\hline S2 & 1.30 & 0.72 & 0.32 \\
\hline S3 & 1.35 & 0.77 & 1.11 \\
\hline S4 & 1.73 & 0.83 & 0.59 \\
\hline S5 & 1.74 & 1.02 & 1.34 \\
\hline S6 & 1.05 & 0.81 & 0.28 \\
\hline S7 & 1.68 & 0.68 & 0.48 \\
\hline S8 & 1.12 & 0.58 & 0.40 \\
\hline S9 & 1.28 & 0.86 & 0.64 \\
\hline S10 & 1.39 & 0.63 & 0.32 \\
\hline S11 & 1.19 & 0.68 & 0.43 \\
\hline S12 & 1.42 & 0.92 & 0.46 \\
\hline
\end{tabular}

Table S2: Non-bonded interaction energy ( $\mathrm{kcal} / \mathrm{mol})$ between solvent, $\mathrm{N}$-terminus, central, and C-terminus regions of different chains for REMD simulation of docking structure. Snapshots are collected at $300.38 \mathrm{~K}$ in [300-600 ns]. Errors represent standard deviation. Self-interaction of solvent is excluded.

\begin{tabular}{|c|c|c|c|c|c|}
\hline & & $\mathrm{N}$-terminus & Central & C-terminus & Solvent \\
\hline Electrostatic & \multirow{2}{*}{ N-terminus } & $33.25 \pm 21.74$ & $\begin{array}{l}-104.29 \pm \\
7.44\end{array}$ & $23.51 \pm 4.96$ & $\begin{array}{l}-1725.79 \pm \\
126.78\end{array}$ \\
\hline $\begin{array}{l}\text { van der } \\
\text { Waals }\end{array}$ & & $\begin{array}{l}-12.03 \pm \\
17.69\end{array}$ & $\begin{array}{l}-19.99 \pm \\
10.50\end{array}$ & $-25.84 \pm 3.47$ & $-16.33 \pm 7.32$ \\
\hline Electrostatic & \multirow{2}{*}{ Central } & $\begin{array}{l}-104.29 \pm \\
7.44\end{array}$ & $\begin{array}{l}-60.15 \pm \\
10.04\end{array}$ & \begin{tabular}{|l|}
$-72.74 \pm$ \\
14.47 \\
\end{tabular} & $\begin{array}{l}-1206.24 \pm \\
187.21\end{array}$ \\
\hline $\begin{array}{l}\text { van der } \\
\text { Waals }\end{array}$ & & $\begin{array}{l}-19.99 \pm \\
10.50\end{array}$ & $-18.75 \pm 2.26$ & $\begin{array}{l}-26.82 \pm \\
11.93\end{array}$ & $-16.77 \pm 7.09$ \\
\hline Electrostatic & \multirow{2}{*}{ C-terminus } & $23.51 \pm 4.96$ & $\begin{array}{l}-72.74 \pm \\
14.47\end{array}$ & $-29.62 \pm 7.41$ & $\begin{array}{l}-576.69 \pm \\
114.16\end{array}$ \\
\hline $\begin{array}{l}\text { van der } \\
\text { Waals }\end{array}$ & & $-25.84 \pm 3.47$ & $\begin{array}{l}-26.82 \pm \\
11.93\end{array}$ & $-23.30 \pm 2.67$ & $-21.00 \pm 7.31$ \\
\hline
\end{tabular}


Table S3: Non-bonded interaction ( $\mathrm{kcal} / \mathrm{mol}$ ) between solvent, N-terminus, central, and Cterminus regions of different chains for REMD simulation of three chains of 2NAO. Snapshots are collected at 300.38 K in [300-600 ns]. Errors represent standard deviation. Self-interaction of solvent is excluded.

\begin{tabular}{|c|c|c|c|c|c|}
\hline & & N-terminus & Central & C-terminus & Solvent \\
\hline Electrostatic & \multirow{2}{*}{$\mathrm{N}$-terminus } & $7.91 \pm 14.63$ & $\begin{array}{l}-107.72 \pm \\
14.30\end{array}$ & $41.98 \pm 7.94$ & $\begin{array}{l}-1774.83 \pm \\
179.37\end{array}$ \\
\hline $\begin{array}{l}\text { van der } \\
\text { Waals }\end{array}$ & & $-18.40 \pm 5.58$ & $\begin{array}{l}-18.20 \pm \\
10.27 \\
\end{array}$ & $-14.70 \pm 9.67$ & $-18.53 \pm 8.28$ \\
\hline Electrostatic & \multirow{2}{*}{ Central } & $\begin{array}{l}-107.72 \pm \\
14.30\end{array}$ & $\begin{array}{l}-99.48 \pm \\
12.21\end{array}$ & $-54.71 \pm 8.00$ & $\begin{array}{l}-1295.01 \pm \\
181.52\end{array}$ \\
\hline $\begin{array}{l}\text { van der } \\
\text { Waals }\end{array}$ & & $\begin{array}{l}-18.20 \pm \\
10.27\end{array}$ & $-34.84 \pm 3.48$ & $-15.91 \pm 5.92$ & $-16.79 \pm 6.44$ \\
\hline Electrostatic & \multirow{2}{*}{ C-terminus } & $41.98 \pm 7.94$ & $-54.71 \pm 8.00$ & $\begin{array}{l}-135.34 \pm \\
12.87\end{array}$ & $\begin{array}{l}-572.96 \pm \\
161.60\end{array}$ \\
\hline $\begin{array}{l}\text { van der } \\
\text { Waals }\end{array}$ & & $-14.70 \pm 9.67$ & $-15.91 \pm 5.92$ & $\begin{array}{l}-54.30 \pm \\
18.47\end{array}$ & $-20.26 \pm 7.30$ \\
\hline
\end{tabular}

Table S4 : Residues in the barrels of S6 and S11 of simulation 1.

\begin{tabular}{|l|l|l|}
\hline \multirow{4}{*}{ S6 } & Chain A & $3-6,18-22,30-41$ \\
\cline { 2 - 3 } & Chain B & $16-25,29-40$ \\
\cline { 2 - 3 } & Chain C & No residue \\
\hline \multirow{3}{*}{ S11 } & Chain A & $18-24,27-36,39-41$ \\
\cline { 2 - 3 } & Chain B & $15-18$ \\
\cline { 2 - 3 } & Chain C & $8-13,16-20$ \\
\hline
\end{tabular}

Table S5: Number of hydrophobic, hydrophilic residues and height of three barrels.

\begin{tabular}{|l|l|l|l|}
\hline & Barrel 6 & Barrel 11 & 3SGR \\
\hline Hydrophilic residues & $15(27.8 \%)$ & $11(30.6 \%)$ & $24(32.4 \%)$ \\
\hline Hydrophobic residues & $39(72.2 \%)$ & $25(69.4 \%)$ & $50(67.6 \%)$ \\
\hline Height $(\AA)$ & 17.2 & 14.4 & 18.9 \\
\hline
\end{tabular}




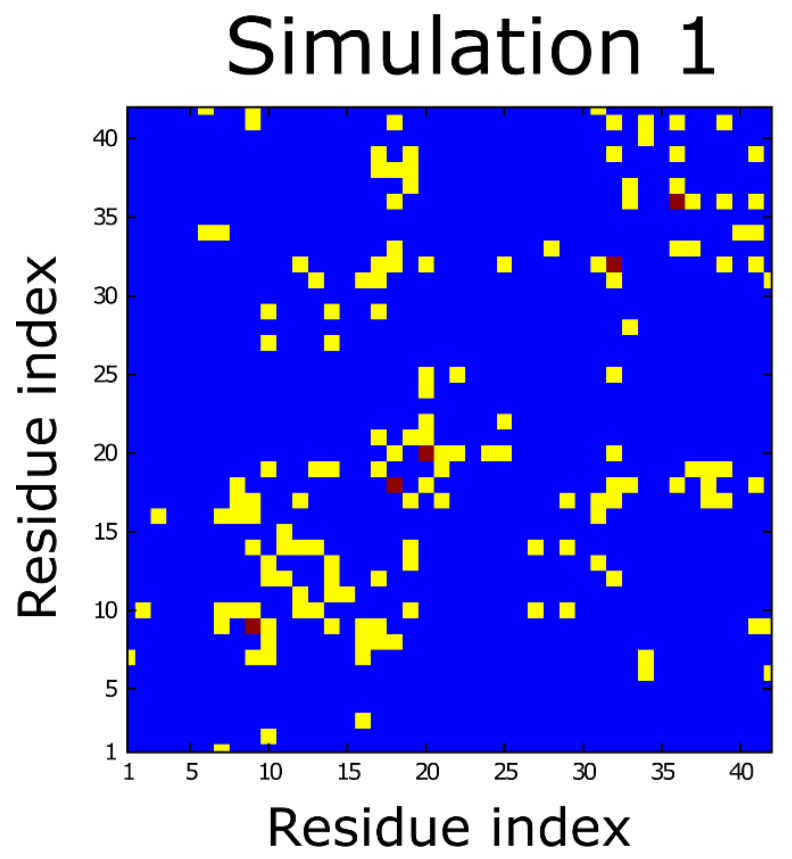

Simulation 2

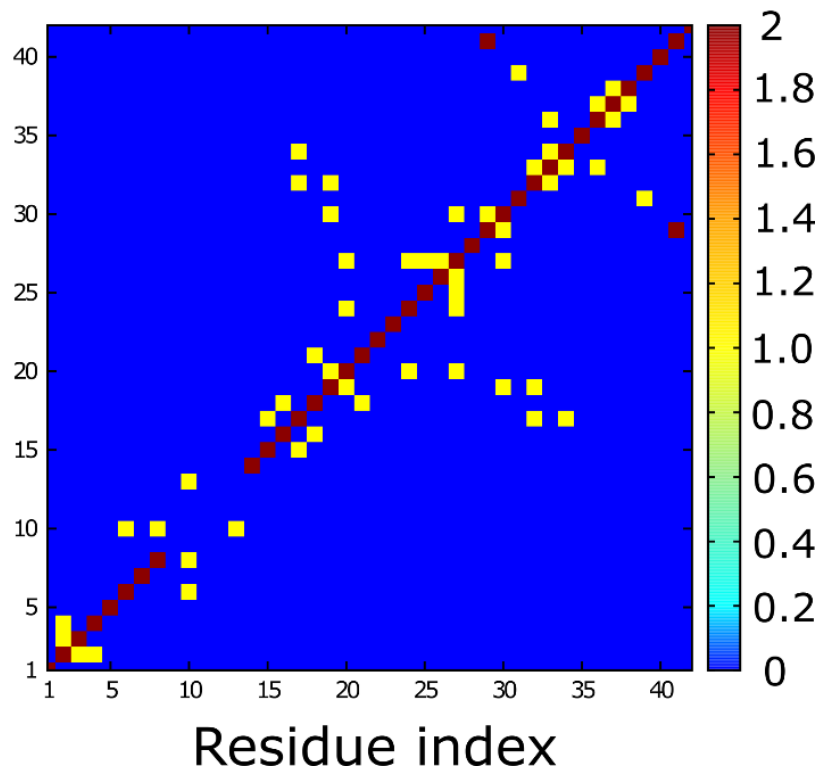

Figure S1: Interchain contact maps of initial structures.

Simulation 1

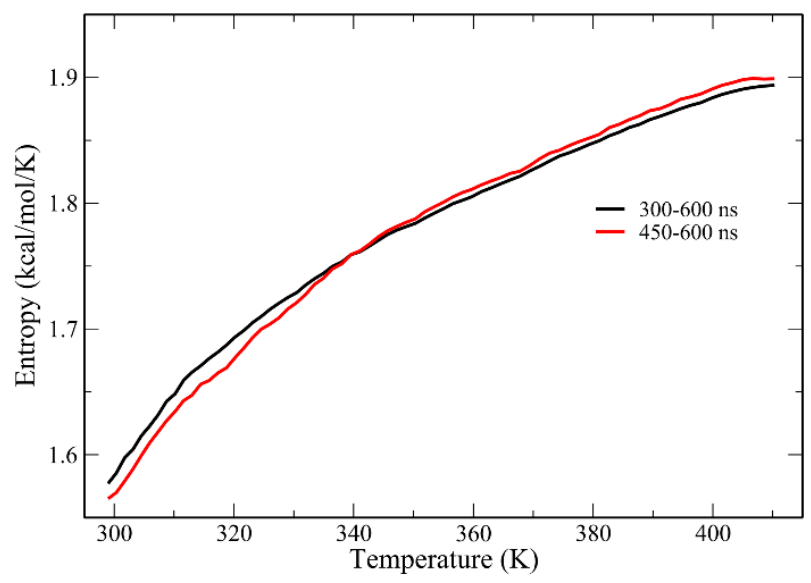

Simulation 2

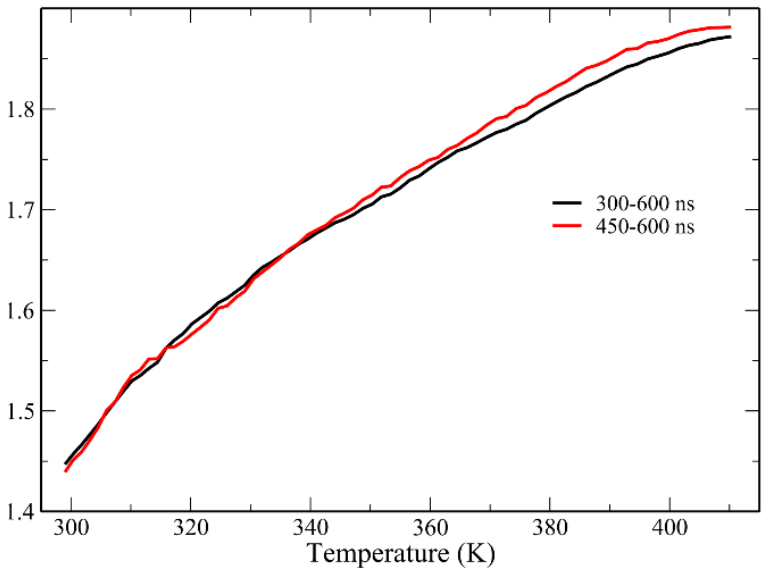

Figure S2: Configurational entropy of trimer A $\beta 42$ in two time-windows [300-600 ns] and [450$600 \mathrm{~ns}]$ 

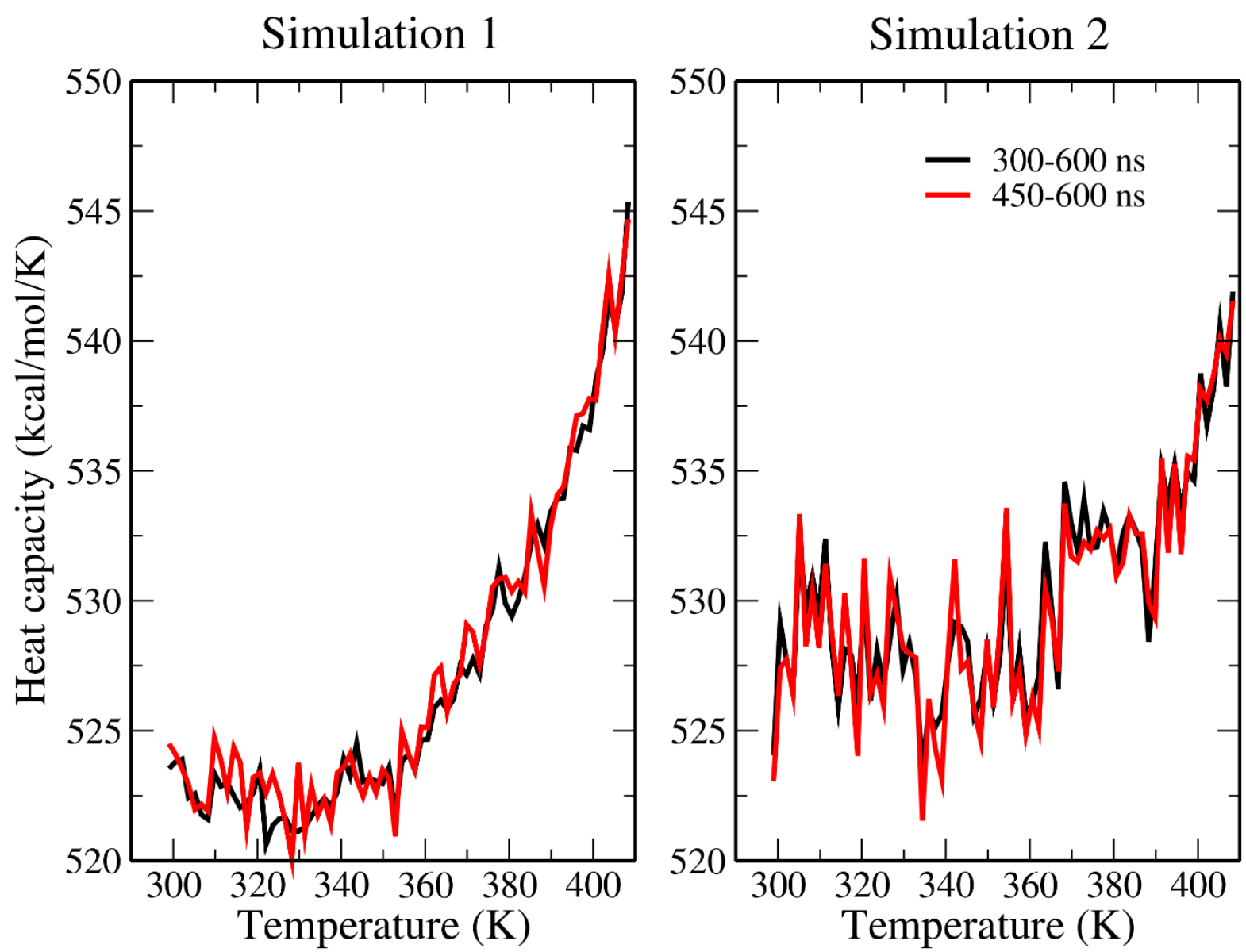

Figure S3: Heat capacity of trimer $A \beta 42$ and solvent in two time-windows [300-600 ns] and [450-600 ns] 

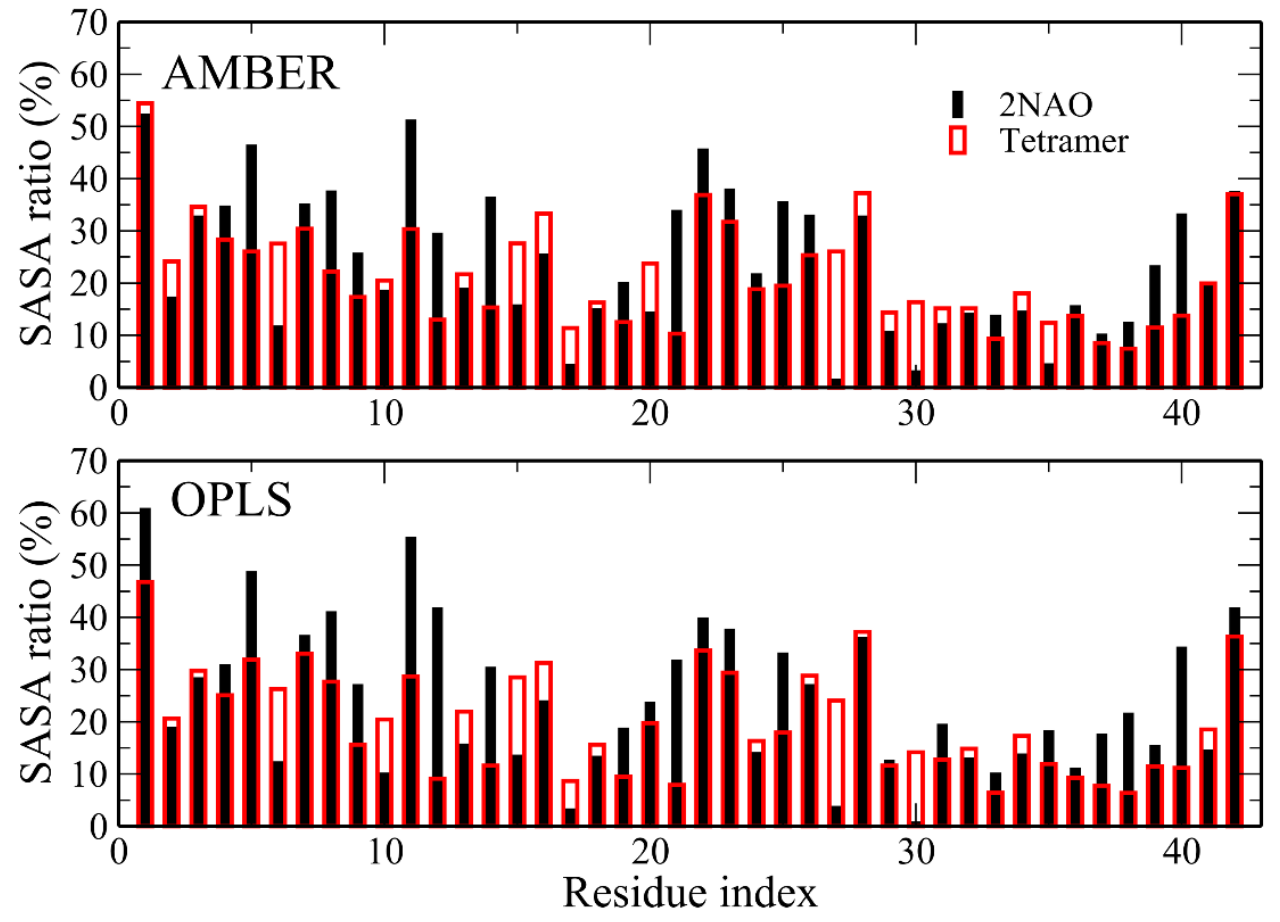

Figure S4: SASA ratio of residues in the $\mathrm{A} \beta 42$ tetramer, 4 chains of $2 \mathrm{NAO}$ and free amino acids. The results for the $\mathrm{A} \beta 42$ tetramer were obtained using simulation data from Linh et al [1].

\section{S6}

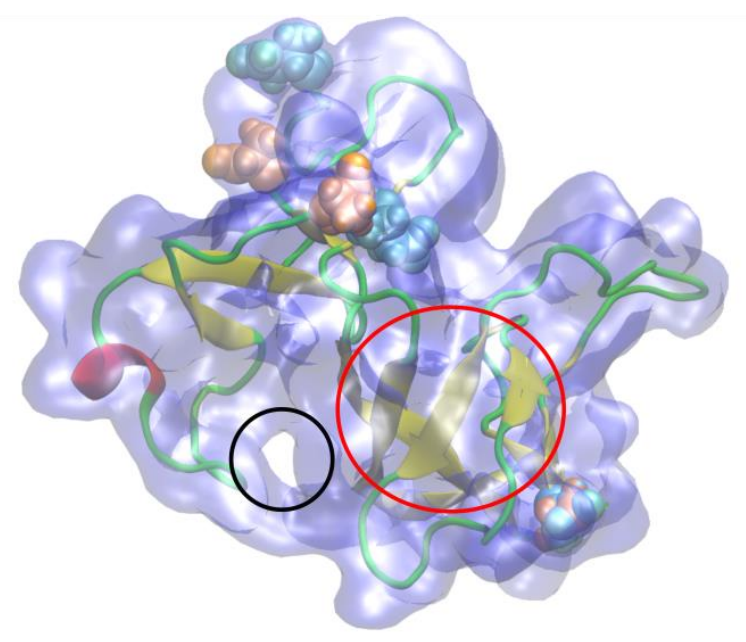

S11

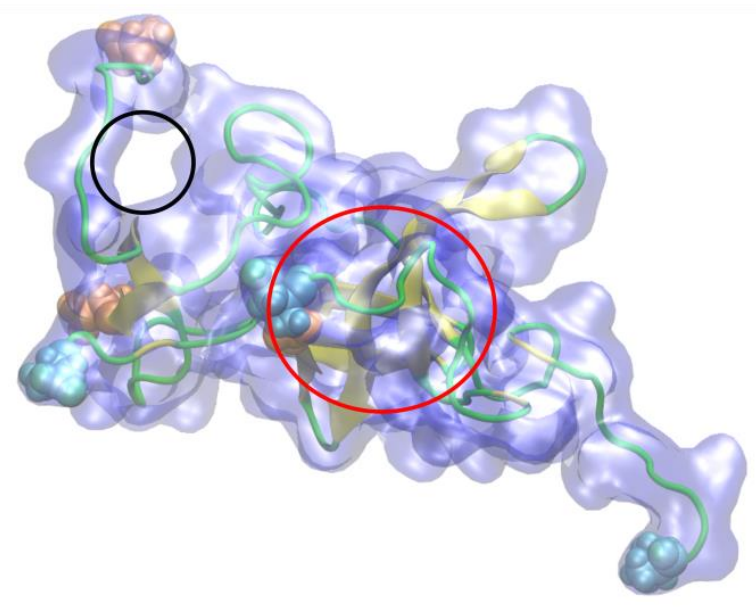

Figure S5: $\beta$-barrel (in the red circle) and pore (in the back circle) are clearly separated. 
Barrel 6

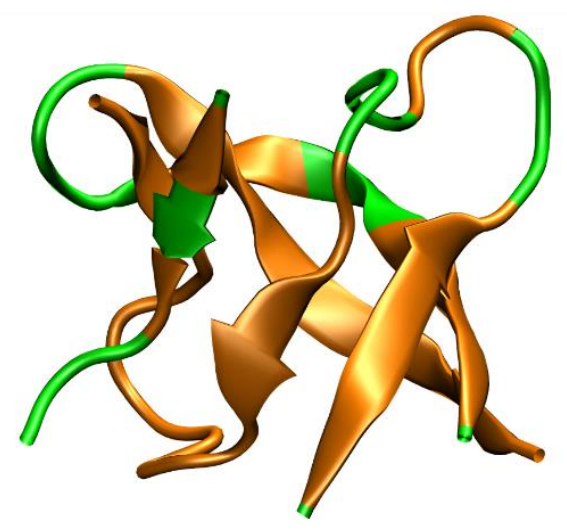

Barrel 11

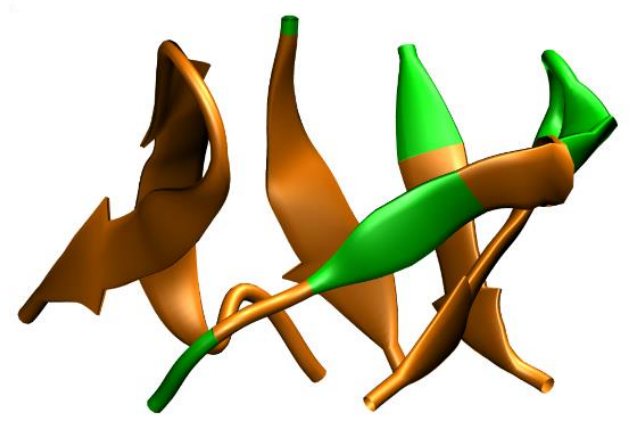

3SGR

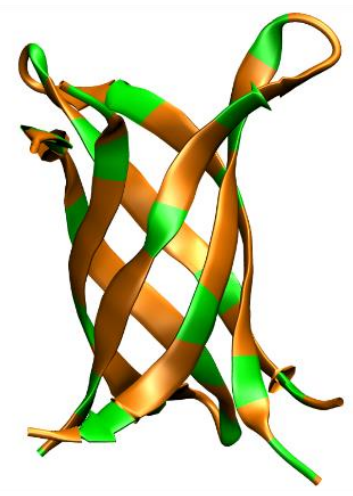

Figure S6: Structures of barrels 6 and 11 obtained in this work and of 3SGR. Hydrophobic residues of barrels are indicated in orange and hydrophilic residues in green. These structures were used as initial structures in simulations with membrane.

\section{trimer $2 \mathrm{NAO}$}

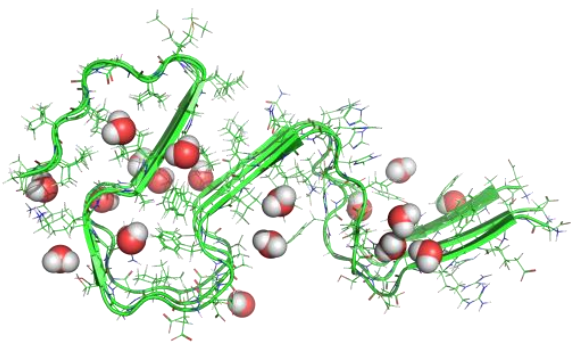

\section{Simulation 1}

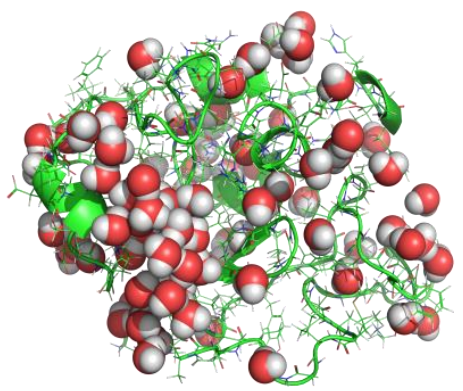

tetramer 2NAO

\section{Simulation 2}

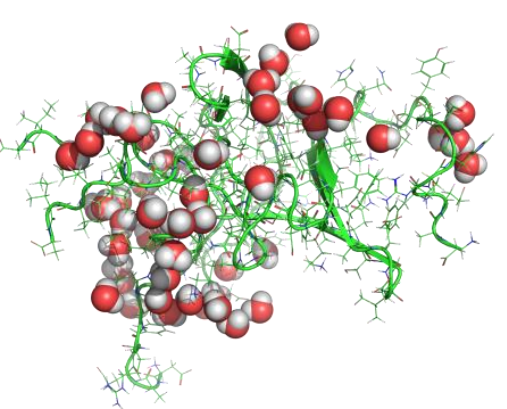

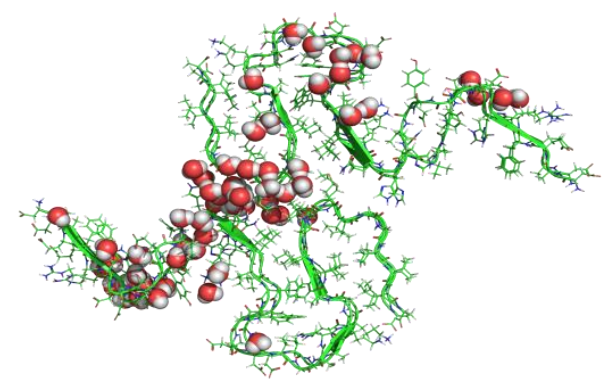

Figure S7: Water molecules inside trimers and tetramers. Their concentration is shown in Table 6. The trimer and tetramer of the $2 \mathrm{NAO}$ structure were obtained by CMD simulation, which started with the PDB structure, and $\mathrm{C} \alpha$ atoms were restrained during the simulation. 


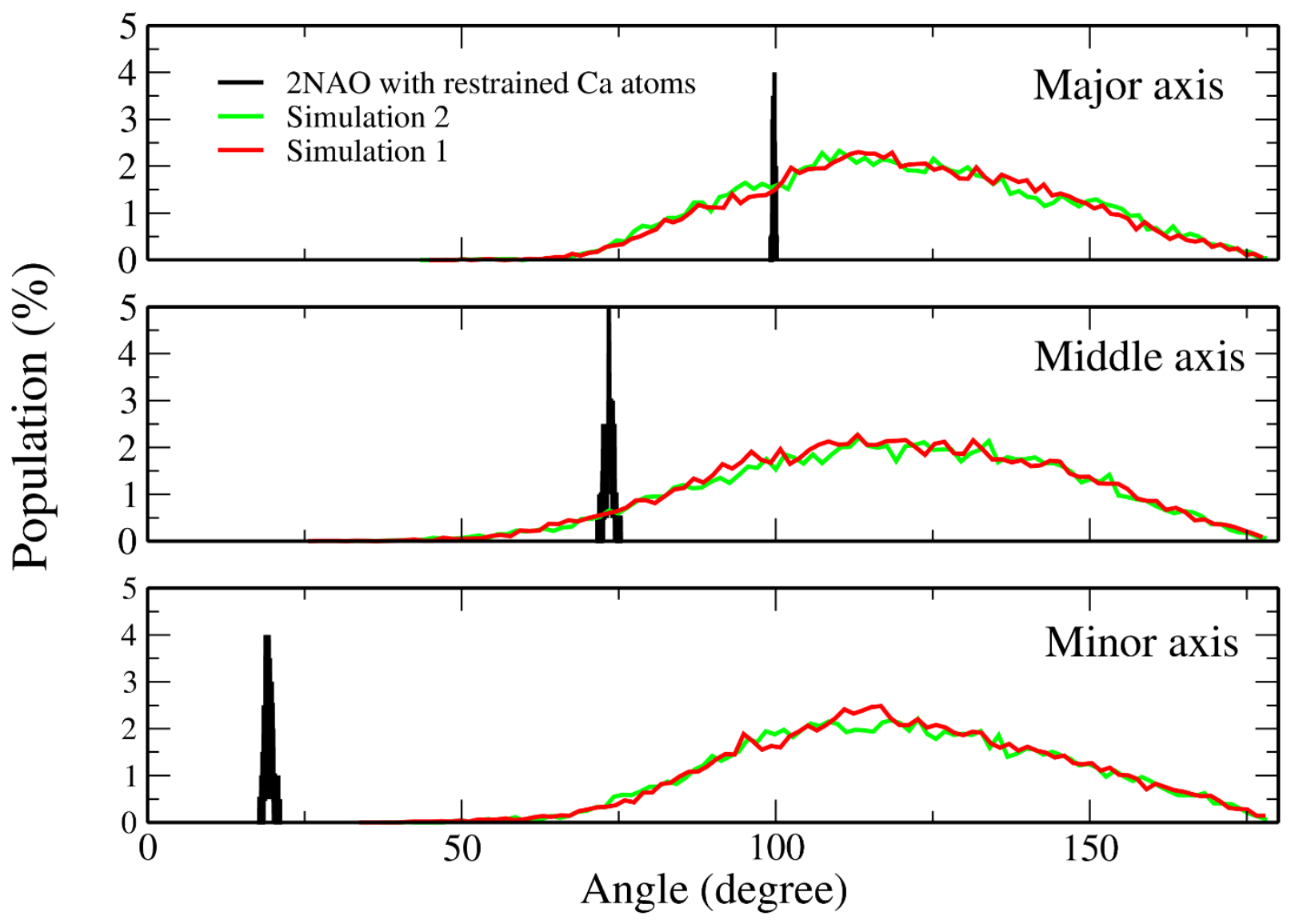

Figure S8: The angles between three components of inertia moment and dipole.

\section{REFERENCES}

[1] Nguyen, H.L., Krupa, P., Hai, N.M., Linh, H.Q., Li, M.S. Structure and Physicochemical Properties of the A 42 Tetramer: Multiscale Molecular Dynamics Simulations. J Phys Chem B. 2019, 123, 7253-69. 